\title{
Business Model for Recycling Traction Battery
}

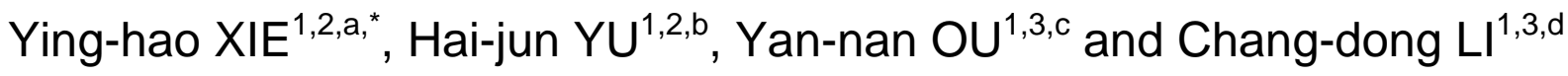 \\ ${ }^{1}$ Guangdong Brunp Recycling Technology Co., Ltd., Foshan 528244, China \\ ${ }^{2}$ Hunan Brunp End-of-Life Vehicles Recycling Co., Ltd, Changsha 410600, China \\ ${ }^{3}$ Guangdong Traction Battery \& Electric Vehicle Recycling Research Academician Workstation, \\ Foshan 528244, China
}

*Corresponding author: diangong306@126.com

Keywords: Traction battery, Recycling, Business model, Policy.

\begin{abstract}
At present, the automotive industry standard, material standards stipulate battery life is not less than 500 times to use during charging and discharging the battery every 1 to 2 times, the battery should be scrapped after 2 to 3 years. At present, our country attaches great importance to waste battery recycling. Since 2006, a policy first proposed the automobile companies have to recycle its sales batteries. So far, three policies or regulations require directly the waste traction battery should be recycling. The main recycling responsibility unit is automobile companies or traction battery manufacturer. The author analyses existing policies and evaluate the trends of policy evaluation based on power battery life characteristics. The author considers that the trends will be coded so that traction battery and electric vehicle bound to carry out registration system. At that time, consumers will initiative to take the waste traction battery to treatment plants. Realize all the traction batteries have been effective recovery in the whole life cycle of electric vehicles.
\end{abstract}

\section{Introduction}

The State Council issued the "Guiding Opinions on Accelerating promote the use of new energy vehicles" in 2014. Related departments issued a series of policy measures including exempt from purchase tax, charging facilities construction rewards, public promotion case and government agencies purchase. The implementation of new energy automotive industry technology innovation projects, and released 78 electric vehicle standards. It boosted the confidence of the automotive industry to develop new energy vehicles. In 2014, China cumulative sales of new energy vehicles is 113,000, annual production is 83,900, including 27,200 in December production, creating a new global energy vehicles in a single month record. The world's new energy bus promotion quantity rank first. By 2014, China's new energy automotive industry development from the introduction stages entering into the early stages of growth.

"Resource - Production - Circulation - Consumption - Waste recycling" closed loop flow is basic requirements to achieve circular economy and clean production. It should consider the impact of their whole life cycle of the environment to achieve the new energy vehicles truly green. Waste Traction battery should also ensure safe, environmentally friendly, reasonable disposal when new energy vehicles scrapped. Waste traction battery is harmful to humans and the environment for containing nickel, cobalt, manganese, electrolyte and other harmful substances [1]. Recycling of waste traction battery is a key to guaranteed electric vehicle the whole lifecycle green. Accordingly, How to recycle waste traction battery has become an important issue.

This paper guide waste battery recycling company reasonably spread recycling network based on the life characteristics of the traction battery, analyze existing policies, and assess future trends, to avoid blind construction on battery recycling system. 


\section{Traction Battery Characteristics and Recycling Policy}

Battery Type. PEV are mainly used lithium ion batteries. The anode material of traction battery are commonly used the $\mathrm{LiFePO}_{4}, \mathrm{Li}\left(\mathrm{Ni}_{\mathrm{x}} \mathrm{Co}_{\mathrm{y}} \mathrm{Mn}_{1-\mathrm{x}-\mathrm{y}}\right) \mathrm{O}_{2}, \mathrm{LiMnO}_{2}$, very few will use $\mathrm{LiCoO}_{2}$ [2]. PHEV are mainly used nickel-metal hydride $(\mathrm{Ni}-\mathrm{MH})$ batteries. The value of waste traction battery is determined by its own material. The value of the above type traction battery descending order is $\mathrm{Li}\left(\mathrm{Ni}_{\mathrm{x}} \mathrm{Co}_{\mathrm{y}} \mathrm{Mn}_{1-\mathrm{x}-\mathrm{y}}\right) \mathrm{O}_{2}, \mathrm{Ni}-\mathrm{MH}, \mathrm{LiMnO}_{2}, \mathrm{LiFePO}_{4}$.

Generally believed that traction battery is no longer suitable for using in electric vehicles when the capacity less than $80 \%$ [3]. There is a great use of space while the capacity is $80 \%$ or less. And the state also support and encourage echelon use. Therefore, waste traction battery according reusability can be divided into two categories, respectively, can echelon use and cannot echelon use. One is can echelon use battery which is remove from electric car and has been tested and meet charging and safety. Another one is cannot echelon use battery which is does not meet charging and safety battery, including replacement batteries in repairing, accident damage batteries, cannot pass the echelon use test batteries.

For the first type of waste traction battery, because of the high value of the echelon use, and will birth echelon use corporate. Recycling unit can be echelon use corporate, battery disposal enterprises. Echelon use corporate will pay a fee when recycling. For the second type of waste traction battery, because of harmless treatment for the separator, electrolyte and other substances, the battery is low-value of recycling. For some materials of battery (e.g. lithium iron phosphate) would be a loss money recovery. Echelon use companies will not recovery this battery, then recovery unit is only battery disposal companies. Battery disposal companies will charge a treatment fee depending on the material type of battery.

Battery Life. Battery design life is 500 charge and discharge cycles. China's automotive industry standards QC/T 743-2006 "Lithium-ion batteries for electric vehicles", QC/T 744-2006 "Nickle-metal hydride batteries for electric vehicles" life was defined as 500 cycles. In fact, the life of battery is consistent with the material life of the battery material standards. The current battery materials standard YS/T 677_2008 "Lithium manganese oxide", YS/T 798-2012 "Lithium nickel cobalt manganese oxide" and July 24, 2014 the latest release GB/T 20252-2014 "Lithium cobalt oxide" specified in the material life of just 500 times. The battery should be scrapped after two years assume that charge and discharge battery once a day.

National standard GB/T 30835-2014 "lithium iron phosphate - carbon composite cathode material for lithium ion batteries" (implementation at April 1, 2015) does not stipulate for the material cycle life. The industry standard of YS/T 1027-2015 "lithium iron phosphate" (approval at January 12, 2015 is not yet released and implementation). Currently on the market lithium iron phosphate material made of lithium-ion battery life is typically 1500 to 2000 times. Due to the low lithium iron phosphate material prices and lower capacity, commonly used in electric buses battery. Electric buses usually Mileage is generally $100 \sim 250 \mathrm{~km}$, it needs to be recharged 1 2 times every day, life expectancy is only $3 \sim 5$ years [4].

Battery life determines the battery need to be replaced several times before electric cars scrapped. In addition, when the car is scrapped, the battery mounted on the electric cars should scrapped at the same time. Figure 1 is waste traction battery source. Accordingly, the amount of waste traction battery will be turned several times with increasing sales of electric vehicles. Our waste traction battery recycling is extremely urgent and important.

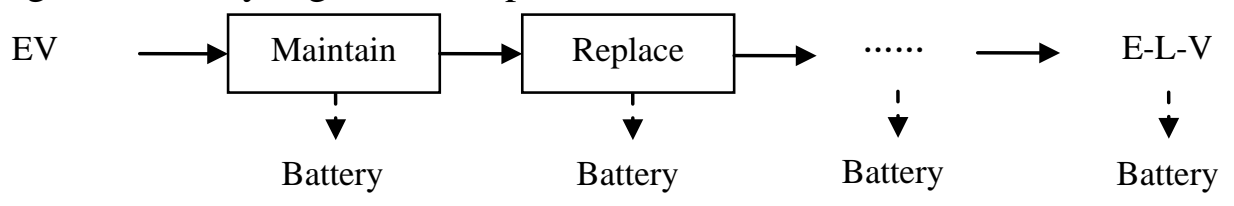

Figure 1 The source of waste traction battery

Recycling Policy. February 2006 Development and Reform Commission, Ministry of Science, Ministry of Environmental Protection jointly developed a "Recycling automotive products 
technology policy." The policy provisions the company of electric vehicles (including hybrid cars, etc.) responsible for recycling, treatment its sales of electric vehicle batteries.

In October 2011, Ministry of Finance, Ministry of Science, the Ministry of Industry, Development and Reform Commission four ministries jointly issued the "Circular on further improving energy conservation and new energy vehicle demonstration pilot work notice" (Finance Office Built [2011] No.149) research to develop new energy vehicle demonstration promotion incentives. In the implementation of the policy, vehicle companies or battery leasing companies should build traction battery recycling system. The companies should implementation of traction battery recycling responsibility, commitment to the relevant recycling services, establish the appropriate treatment capability.

In April 2012, the State Council issued the "Energy-saving and new energy automotive industry development plan (2012-2020)" (National Development [2012] No. 22), stipulate for the BEV is the main strategic orientation of the automotive industry in transition, development battery recycling management methods, and establish traction battery cascade utilization and recycling management system, clear responsibilities, rights and obligations of all relevant parties. Boot battery production enterprises to strengthen the recycling of waste batteries, encourage the development of professional battery recycling companies.

Development and Reform Commission is currently being developed "electric vehicle traction battery recycling technology policy". In order to put forward for China's electric vehicle battery recycling overall framework, exploring the use of funds, deposit, mandatory recycling and other ways to promote waste traction battery recycling, and promote the establishment of a sound waste traction battery recycling system.

From the above policy analysis shows that the three current existing recovery policy has two main responsibility, car companies and battery manufacturers. The main responsibility transform from 2006 "policy" provisions of car companies to 2012 "planning" provisions of battery manufacturers. The reason may be based on consideration of the producer responsibility system.

\section{Recycling Mode}

Producer Responsibility. Producer responsibility is one of the major institutional principles of modern environmental management system to achieve product environmental performance improvement. It is the tradition principles of the "polluter pays" deepening and extending. The central idea is to refer to the original producers of products for environmental responsibility extends to the entire life cycle of products, not only in the production and use of the product, which also includes waste products recycling and disposal [5]. Producer responsibility system is currently small battery pollution prevention and control major system in EU. The recycling model requires further study for the applicability of our country traction battery recycling.

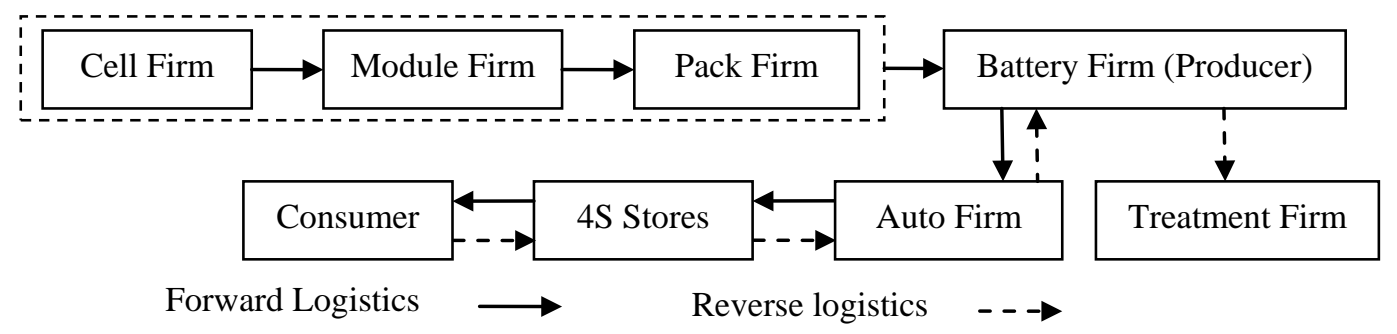

Figure 2 Recycling mode of producer responsibility

Figure 2 is a producer responsibility recycling mode. In this recycling mode, waste traction battery reverse logistics return along the new battery source. Due to the special nature of the structure of the traction battery itself, traction battery manufacturers can be split into cell manufacturer, module manufacturers and pack manufacturers. Currently the traction battery on the market circulation, cell, modules and pack producer may vary. As a German brand automobile companies buy the cells from South Korea and assembled into a pack in Germany mounted on the electric car exports to China. In 
this case, the producer is not easy strict division, even after the division the responsibility is not conducive due to differences country producers. On the other hand, traction battery producers get the waste traction battery from consumers is extremely difficult. The terms of the Fig. 1 reverse logistics road recycling waste traction battery, this time cannot guarantee the consumer, traction battery producers, 4S stores and car manufacturers will provide free and convenient traction battery recycling services. If paid for the services, it will increase recovery cost for frequently transactions and transportations. It is not conducive to battery recycling.

Automobile Companies as the Mainstay. The recycling mode of automobile companies as mainstay is shown in Figure 3. Traction battery scraped before the electric car due to the battery life or the improper use by consumers. Automobile companies should responsibility for recycling the repair or replace traction battery. Automobile companies can take advantage of the rich resources of the $4 \mathrm{~S}$ store for recycling.

Cell itself metals and secondary usable make battery has value. This part of the value can be deducted packaging, transportation and other expenses generated during of the recovery process. At the same, It is more conducive to guarantee technology, design and other trade secrets of traction battery from disclosure due to the shortening of the recovery process, automobile companies provide directly to the waste battery treatment plant. Automobile companies can be obtained the degree of difficulty treating different types of waste traction battery from treatment plant. So this can feedback to guide the automobile companies take dismantling and disposal of end of life battery into account before designed production, to achieve green design.

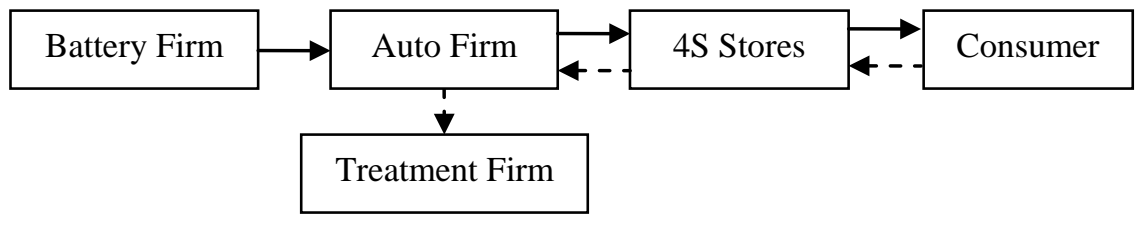

Forward Logistics

Reverse Logistics $\quad-\rightarrow$

Figure 3 Recycling mode of automobile companies as the mainstay

Mandatory Recycling. Ministry of Public Order No.102 "Motor vehicle registration requirements" provision the traditional fuel vehicle engines must be registered before used. Electric car without using an engine, meanwhile, traction battery is power source of new energy vehicles. The position of traction battery is tantamount to "five assembly" on traditional fuel vehicle, which encodes the traction battery and binding with the electric car. China is studying the implementation of coding and registered for use in new energy vehicles [6]. Once the policy was implemented, car owners should go to the relevant departments cancellation declaration when electric vehicles or traction battery scrapped. Then give or sell to traction battery treatment plant to receive "motor vehicle scrapping prove" complete write-off, before purchase of a second car.

This recovery model is forced consumers to hand over traction batteries, so ensure that the final mounted on scrapped car battery can be effectively recovered. In order to ensure the whole life cycle of the electric car battery have all been effectively recovered, car owners need to record in the relevant departments when the battery was replaced in the process of using electric cars.

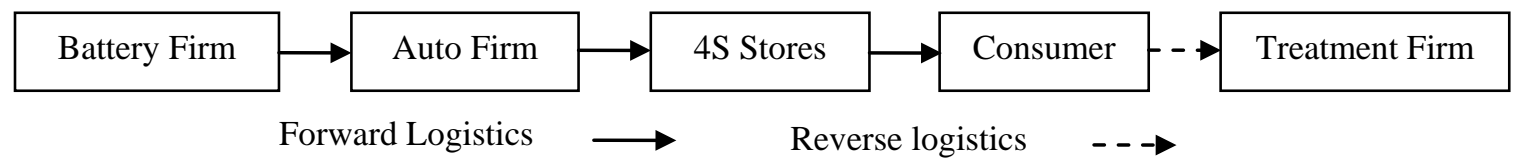

Figure 4 Mandatory recycling model

\section{Summary}

Current automotive industry standards, material standards are specified battery life is not less than 500 times, the battery will scrap after use 2 to 3 years in the condition of charging and discharging the battery 1-2 times a day. Currently, China attaches great importance to waste traction battery recycling. 
Since 2006, the first time put forward automobile companies should recycle their sales of traction batteries. There has been three policies, regulations directly require waste traction battery should be recycling. The main recycling responsibility unit is automobile companies or traction battery producers. In terms of traction battery producers responsibility for the main recycling responsibility unit may be due to the long recovery process, more exchange times lead to high recovery costs, is not conducive to recovery. In terms of automobile companies responsibility for the main recycling responsibility unit is more conducive to protect business trade secrets while also feedback to guide green design. At current trends, traction battery will encoded and binding with electric vehicles then registered for use in new energy vehicles. Then car owners will take the initiative to hand the waste traction battery to treatment plant to realize the whole life cycle of electric vehicles all the traction batteries is effectively recovered.

\section{Acknowledgement}

This research was financially supported by the national Torch Program projects (No. 2013GH061426), National Key Technology R\&D Program alternative project (subproject) (No. 2014BAC03B01) and strategic emerging industries core technology research projects in Guangdong Province (No. 2011A032302001).

\section{References}

[1] Y.H. Xie, H.J. Yu, Y.N Ou and C. D. Li, Environmental impact assessment of recycling waste traction battery. Inorganic Chemicals Industry, 47(2015)43-46.

[2] H.J. Yu, Y.H. Xie, Y.N Ou and C. D. Li, Research on storage security of waste battery for electric vehicle. Chinese Journal of Power Sources, 39(2015)745-748.

[3] H.J. Yu, T.Z. Zhang and J. Yuan, Trial study on EV battery recycling standardization development. Adv. Mater. Res., 610-613(2013) 2170-2173.

[4] H.J. Yu, Y.H. Xie and T.Z Zhang, Technical progress on power batteries recovery for electric vehicle, The Chinese Journal of Nonferrous Metals, 24(2014) 448-460.

[5] J. Han and S.W. Chen, Waste battery management and recycle treatment at home and abroad. Environmental Sanitation Engineering, 10(2002) 177-179.

[6] H.J. Yu, Y.H. Xie and Y.N Ou, Industry exploration dismantling and recycling of new energy vehicle in our country, Environmental Science and Technology, 27(2014) 66-69. 